\title{
Estados primitivos da mente. O trabalho onírico no encontro analítico
}

\author{
Conceição Melo Almeida
}

\begin{abstract}
Resumo
A autora desenvolve uma reflexão teórico-clínica acerca dos estados primitivos da mente, definindo o conceito em diálogo com outros conceitos clássicos em psicanálise. Seguindo uma linha conceptual que vai de Freud, aos contributos de Klein, Winnicott, Bion e Green, procura demonstrar a presença dos estados primitivos da mente no processo psicanalítico. Coloca, ainda, em evidência o trabalho onírico como instrumento que veicula o acesso e a transformação dos estados não representados, hipótese que ilustra clinicamente a partir da apresentação e discussão do material psíquico da análise de uma criança.
\end{abstract}

Palavras-chave

Estados primitivos da mente, Inconsciente, Rêverie, Transformações psíquicas.

\section{Pensamentos oníricos}

Dança com lobos

Luís, com oito anos, tinha desaparecido da instituição ao início do dia. Foi procurado, sem sucesso. Deixei recado para quando o encontrassem - eu estaria ali. Perto da hora de ir embora, vindo do vão das escadas, começo a ouvir... um uivo. Era Luís. Estaria a fazer de conta? Ou não saberia fazer de conta? Aquele uivo errante ecoou num ponto do meu infinito. O uivo errático procurava abrigo. Veio-me a imagem da «dança com lobos». Respondi em uivo também. Luís saiu do «buraco», subiu as escadas, pesado, balofo, encharcado, enlameado, falando esta imagem muito para

\footnotetext{
1 Psicanalista de Crianças, Adolescentes e Adultos. Membro Titular da Sociedade Portuguesa de Psicanálise.

E-mail: conceicao.m.almeida@hotmail.com

(C) do Autor 2021. Publicado online em https://rppsicanalise.org, sob a Licença Creative Commons Atribuição-NãoComercial 4.0 Internacional. Seguindo a exigência da preservação do anonimato dos pacientes e da confidencialidade, o material clínico é apresentado com alteração da identidade do paciente e de dados clínicos.
}

lá do sensorial. Na sala, em silêncio, olhou fixamente os meus olhos cerrados, passou o braço com a roupa molhada por toda a superfície do tampo da mesa, deixando quiçá as marcas possíveis da sua segunda pele. Olhou-me fixamente de novo, mas agora ele era o pequeno Luís, os dois num holograma, e estávamos no meu consultório. Deitou-se no divã, sem idade, e perguntou: «Conceição, que ésonhar?»

\section{Redenção}

Édipo dirige-se a Sísifo — «Julgam-me por vezes o herói conquistador, até arrogante. Matei pela verdade, decifrei o enigma como Sherlock, casei com a rainha e reinei. Mas por isso mesmo me infligi a cegueira e tenho de viver com a dor. Compreendo, no entanto, Sísifo, meu irmão, que te seja impossivel, por hora, tolerá-la. Desculpa-me se te vi repetitivo. Posso ver-te agora como corajoso. Afinal ensinaste-me que em psicanálise não há repetição estéril. Outras turbulências porvirão. Porque a demanda do trabalho sobre a 
mente é perene. E a função alfa permanecerá como a pedra rolante.»

\section{INTRODUÇÃO}

Neste artigo pretendo demonstrarapresença dos estados primitivos da mente no processo psicanalítico, situando-os metapsicologicamente como um conceito a par de outros conceitos clássicos da psicanálise, teórica e clinicamente mais bem delimitados, tais como o inconsciente, o ego corpóreo, a recaptura de memória e o infantil. Por outro lado, será atribuída uma importância particular ao modo como se manifestam na clínica e exploradas as consequências que têm na técnica, com implicações no modo de conceber a transferência-contratransferência e a interpretação.

Apresentarei e debaterei a noção de trabalho onírico enquanto promotor das mais profundas mudanças psíquicas, procurando salientar a importância da experiência de ser ou de vir-a-ser, além do conhecer.

\section{AS ORIGENS EM FREUD}

Nos seus textos, Freud utilizou algumas vezes a expressão mente primitiva e enfatizou a ideia da primitividade, mas nunca avançou propriamente com uma definição do conceito. No entanto, todo o seu trabalho foi atravessado por uma linha de força marcante, intimamente ligada à condição da mente primitiva - a ideia do negativo e duas direções: a descoberta do inconsciente estruturado, onde as associações estão organizadas, o fenómeno manifesto tem um significado e a análise decorre na procura desse mesmo significado; e a descoberta daquele inconsciente que não está formado ainda. Ao falarmos do que tem de ser criado ainda, pela primeira vez, falamos do vazio, outra noção central no conceito de mente primitiva. Embora Freud tenha captado esta direção não a desenvolveu de forma sistemática.

Revisitarei, assim, o seu pensamento - onde o seu trabalho clínico o levou a reconhecer a necessidade de mudanças nas suas teorias e na estrutura da mente - partindo dos aspetos e con- ceitos que foram considerados pontos de viragem ou revoluções, percursores das principais linhas de uma psicanálise alargada à compreensão e trabalho dos estados primitivos da mente.

\section{A descoberta da pulsão de morte}

Em Além do Princípio do Prazer (1920), Freud concebe a pulsão de morte como um tropismo inato que guia o organismo em direção à morte, atuando de forma silenciosa e permanente, quando sente a presença ou eminência de mudanças, podendo sobrepor-se ao princípio do prazer.

Esta descoberta traz um contributo para a compreensão do dinamismo e do destino dos estados primitivos, também na sua vertente positiva, imprescindível à vida e ao crescimento psíquico, contrariamente a leituras que o associam apenas à destrutividade maligna.

Enquanto ameaça, pode ser responsável pela destrutividade diante do novo e do diferente, não por si só, pois não existe numa forma «pura» ou em abstrato, isolada, mas numa interação pulsional e no encaixe com o ambiente mais ou menos providenciador da satisfação primária (Roussillon, 2015). Em simultâneo, na sua componente benigna, com uma bem-vinda direção nirvânica de retirada da dor mental, como promotora do vazio positivo dos estados de relaxamento e de pausa mental que frequentemente precedem o ato criativo.

\section{O inconsciente não reprimido da segunda tópica e o ego corpóreo}

Também o modelo topográfico se tornou insuficiente para Freud. A segunda tópica será um novo epicentro de revisão conceitual do funcionamento do aparelho mental.

Em O Ego e o Id (1923), Freud reconhece a existência de toda uma outra dimensão, de uma parte não reprimida, não representada do inconsciente, e do ego, que o levou a introduzir uma revisão no modo de abordagem do aparelho psíquico.

É também nesta obra que surge uma outra 
mudança - o culminar da ideia do ego corpóreo, onde é afirmada, contrariamente ao início, a importância da experiência corporal na base do psiquismo: «O ego é em primeiro lugar e acima de tudo um ego corporal; não é meramente uma entidade de superfície, mas é em si mesmo a projeção de uma superfície.» (Freud, 1923, p. 16)

Intercetando esta vasta dimensão do inconsciente não representado com a noção de egocorpóreo, aproximamo-nos da ideia bioniana de sistema protomental, ainda sem a matriz grupal/ relacional, e da ideia de estados muito primitivos da mente. A experiência corporal fica, assim, inexoravelmente ligada à noção de construção e de trabalho inacabado e o psiquismo é algo que começa a constituir-se a partir das primeiras sensações corporais, que, por sua vez, deixarão impressões à espera de representação.

\section{A mudança na noção de sonho e o conceito charneira de construção}

De acordo com Botella \& Botella (2013), podemos identificar no pensamento de Freud duas outras revoluções. A primeira é o abandono da noção de sonho como realização de um desejo infantil - em 1932, dez anos depois da introdução do Id - para ser substituída pela tentativa de realização. A tarefa do sonho não seria mais uma questão de realização, mas uma necessidade imperativa de representação em alternativa à compulsão para repetir. A função primordial da vida psíquica seria então criar representações, permitindo ao trauma não representado ser integrado na cadeia representacional (Freud, 1932; Botella \& Botella, 2013). Ainda segundo estes autores, Freud reintegra desta forma a sua metapsicologia do passado, como memória-ecrã, e a questão do significado (Freud, 1899), abandonada depois de 1900 em prol da teoria da neurose, que na sua fase tardia passa a ocupar apenas uma pequena parte das suas investigações.

Outra dessas revoluções seria com Construções em Análise (Freud, 1937). Em 1905 tinha sido enunciado o carácter limítrofe da pulsão como primeiro elo entre as origens biológicas do indi- víduo e o seu desenvolvimento psicológico. $\mathrm{Na}$ obra de 1915, Os instintos e suas vicissitudes, não só esta noção é reafirmada como é expresso explicitamente um último elemento - a ideia de uma exigência de trabalho ou de transformação sobre a mente, base da formação do símbolo. Para Botella \& Botella (2007), infere-se também que, subjacente à expressão moções pulsionais - desde o nascimento, todos os dias e a cada momento —, o psiquismo tem de ter o que mais tarde Green viria a referir como sendo um travail de representance (trabalho representacional).

Podemos assim ver em Construções: «Muito frequentemente não conseguimos ser bem-sucedidos trazendo o paciente a recordar o que foi reprimido. Em vez disso, se a análise for bem conduzida, produzimos nele uma segura convicção da verdade da construção, que alcança o mesmo resultado terapêutico que uma memória recapturada.» (Freud, 1937, p. 171). Não só a noção de regressão é alargada, como a ideia de convicção (Freud, 1914) se torna também independente da recaptura de memória, sendo algo mais complexo do que o relembrar.

Ainda em Construções, Freud apresenta situações de exceção, destacando a força de alucinações que ocorriam não apenas no caso de pacientes psicóticos, mas também em não psicóticos, e que poderão ser uma referência a registos primitivos sem tradução. Vem a referir-se também, em Moisés e o Monoteísmo (1938), ao carácter não representado das situações traumáticas primitivas, considerando que elas se tornam traumáticas em função de um fator quantitativo, levando a um esquecimento radical. Daqui, podemos inferir uma ligação à noção de trauma em Ferenczi (Favero \& Rudge, 2009) e ao que Roussillon (2011) considera como diferença entre trauma primário ou agonia primitiva e trauma secundário. O primeiro dizendo respeito a uma experiência precoce subjetiva e faseada, que se poderá tornar gradual e massivamente traumática consoante a resposta do meio, com influência na simbolização primária e no modo como esta será integrada no processo secundário.

Não tendo desenvolvido muito acerca do irrepresentável, também no que respeita ao acesso 
a essa dimensão, Freud deixou em diferentes momentos a questão de a consciência ser claramente insuficiente como órgão sensorial para perceção da qualidade psíquica. A este propósito, Fernanda Alexandre (2014) relembra-nos uma citação do pai da psicanálise: «quanto mais procuramos encontrar o nosso caminho para uma conceção metapsicológica da vida mental, mais devemos aprender a emancipar-nos da importância do sistema de ser consciente» (apud Alexandre, 2014, p. 21).

\section{A noção de estados primitivos da mente}

O conceito de estados primitivos da mente, equivalente à expressão mente primitiva, diz respeito a todos os eventos inaugurais do psiquismo, ou seja, aos estados precoces próprios do ser que nasce incompleto, procurando amadurecer numa matriz relacional. Contudo, na teoria psicanalítica, foi prevalecendo um contínuo entre a primitividade e a psicose, embora existam diferenças que consideramos importante mostrar.

De acordo com De Masi (2009), o primitivo para Freud era equivalente à noção de ponto de fixação, associado ao trauma e ao recalcamento originário de representações não toleradas pela consciência. A doença representava, pela via da produção mental do sintoma, o retorno a esse ponto específico do desenvolvimento infantil, considerado um estádio primitivo do desenvolvimento. Também Klein acreditava que todas as crianças passavam por uma fase psicótica e que só algumas a superavam completamente.

Para ilustrar as diferenças, De Masi fala da gratificação alucinatória no bebé e no psicótico. Diz-nos que no bebé este estado tem uma duração limitada. A necessidade física, como a fome, assinala-lhe a perda de contacto com a realidade, fazendo emergir do estado de omnipotência e levando-o a poder percecionar uma falta que evoluirá para a perceção da dependência da realidade. A bondade da resposta atempada do objeto externo coincidirá com a progressiva diminuição da omnipotência primitiva em favor de um contexto de relações de objeto mais realistas. No psicótico, a ausência desta resposta faz com que mecanismos como a decatexia e a forclusão se sobreponham em favor de uma homeostasia emocional contra a dor objetal, e o desligamento da realidade prevalece. Portanto, algo desde o início, de uma outra natureza.

Caper (1998) refere também a questão do infantil perverso polimorfo, relembrando que Freud (1905) pensou a perversão como um retorno no adulto à sexualidade polimorfa do bebé, marca da imaturidade própria do desenvolvimento. Todavia, contrariamente à sua visão inicial, veio a reconhecer a destrutividade característica da perversão como sendo de uma natureza completamente diferente do polimorfismo sexual infantil.

Prosseguimos agora no sentido de uma outra diferenciação - entre o primitivo e o infantil. Refere Roussillon (2011) que a dimensão infantil não é homogénea, mas, sim, organizada em duas fases, sendo a primeira um conjunto de características muito específicas, pertencentes ao período mais precoce, que chama de «estados primitivos da mente». Nesta fase primitiva, a questão principal é a diferenciação entre o eu e o não-eu, com oscilações entre a vinculação e a diferenciação do objeto até que o sujeito descubra a sua existência como outro sujeito. Corresponde também ao período antes da aquisição da palavra. A outra fase, posterior, estrutura-se em torno da diferença entre os sexos e as gerações, e é esta que Roussillon designa por dimensão infantil propriamente dita.

Numa definição abrangente, Symington e Symington (2014) afirmam que o conceito de primitividade diz respeito ao conjunto de experiências iniciais do bebé, ligadas à omnipotência primitiva, às vivências de abandono, à segurança e sua perda, ao terror, à necessidade de se conter a si mesmo para sobreviver e ainda ao desenvolvimento de um pensamento rudimentar chamado de unidimensional. De um outro vértice, Levine, Reed e Scarfone (2013) definem a mente primordial como um nível de organização e inscrição de estados ou fenómenos que não podem ser considerados psíquicos ainda, mas, sim, protopsíquicos, e que, mediante condições ótimas, poderão fornecer material 
para serem transformados em estados «somente» psíquicos.

Será pelo encontro da comunicação primitiva - a identificação projetiva - com a rêverie materna e a função alfa que as antecipações somáticas se transformam em emoções, e as emoções em pensamento. Interligando o não-representado ainda com a questão do autoerotismo, temos um sexual primordial alucinatório, com potencialidades para se poder transformar em sexualidade saudável, se esta for libidinalmente sinalizada nas zonas erógenas pelo investimento da mãe erótica, que passará o seu amor através do leite, pela rêverie, ou seja, pela atenção relaxada (Vermote, 2019).

O negativo desta situação poderá resultar na perda de contacto com a realidade ou ainda na bipolaridade apatia-mania. Quando nos fala em termos de experiências arcaicas, referentes a um período que precede o domínio da linguagem verbal, presentes na mente do adulto ou do adolescente, Roussillon (2011) diz que o trauma massivo ligado às falhas da função objetal é o diferenciador entre vertente normal e desarmónica.

Também Tustin $(1981,1990)$ nos deixou todo um legado acerca dos estados autistas, anteriores à posição esquizoparanóide, existentes mesmo em pacientes neuróticos. São como que inorgânicos, sem vida, uma espécie de «concha» protetora que forma a barreira autista e onde em vez da identificação projetiva encontramos a equação adesiva dirigida a uma superfície e não a um objeto.

Outro importante contributo para a compreensão do mundo interno primitivo, que aqui não desenvolveremos, foi o de Meltzer (1992, 2008). Deixou-nos uma compreensão geográfica da vida mental e a descoberta do espaço interno da mãe interna, aprofundando o conceito de identificação projetiva. A partir dos seus trabalhos sobre a masturbação anal, defendeu a ideia de que o «drama da identificação projetiva se passa no interior da mãe interna, como consequência da projeção/intrusão na mãe externa» (Sousa, 2017, p 23). Através da sua Teoria do Claustrum, podemos perceber o destino patológico da identificação projetiva, operando no objeto interno fruto de uma intensa intolerância à separação.
Num outro polo fenomenológico da vida mental, Meltzer formulou o conceito original de conflito estético, como conflito entre a possibilidade de encontro com a beleza do interior da mãe interna, a partir da externa, e a tolerância à incerteza desse enigma sublime.

\section{Klein e a teoria da mente primitiva}

Foi a partir de Melanie Klein que os estudos acerca da mente primitiva ganharam destaque, muito através do seu trabalho inaugural no plano conceptual e técnico com crianças pequenas e perturbadas com psicose. Foi também ela a formular pela primeira vez uma teoria da mente primitiva.

Com esta formulação, muda a ênfase da ideia de ego corpóreo, do desenvolvimento libidinal e dos estágios libidinais, para a noção de oscilação permanente através da teoria das posições, dos mecanismos de defesa (Farate, 2018) e do importante conceito de identificação projetiva. A mente primitiva surge então com uma dimensão que, embora relacionada com funções do id e do ego, este último por ela postulado como existindo desde o início, tal como o superego rudimentar, não coincide com estas instâncias psíquicas, mas como que as ultrapassa e contém.

A mente primitiva era, assim, concebida como um universo de objetos internos, relacionados entre si através das fantasias inconscientes, constituindo a realidade psíquica. E estas fantasias inconscientes eram os conteúdos inconscientes primordiais, inatos, que constituem transformações narrativas sensoriais iniciais a partir de impressões sensoriais ou estímulos internos e externos - memories in feelings. Dê-se nota que Klein não elaborou muito sobre elas, mas explicou que não são verbalizáveis, não são traduzíveis por palavras, são sentimentos corporais, parecendo ser este o seu modo de chegar aos estados não representados da mente.

Por sua vez, os objetos poderiam ser totais ou parciais, estes últimos representados anatomicamente pelo mamilo, seio, pénis, permanentemente dissociados em bons ou maus, idealizados 
ou persecutórios. Sendo parte da pulsão, estes objetos parciais, que Bion viria a chamar de preconceções, são também as características que organizam o mundo interno primitivo.

Pela aceitação da pulsão de morte, explica a crueldade do superego primitivo, que adotou como fonte primária dos impulsos agressivos e de ansiedades, e a inveja primitiva, inata também, independente da frustração externa e induzindo à angústia de desintegração e aniquilamento.

Ao contrário de Freud, Klein veio demonstrar que a análise é um método de tratamento para as questões narcísicas e para a psicose. $\mathrm{O}$ seu impacto foi não nos limitar neste ponto. Sem dúvida que a combinação entre o trabalho nestas situações e o tratamento de crianças permitiu uma grande evolução. Se entendermos as ansiedades primitivas e as pudermos interpretar quer seja um neurótico, um psicótico ou uma criança, temos os instrumentos necessários para transformar, pois para Klein só se pode ter desenvolvimento se libertarmos o paciente desta ansiedade primitiva.

E este é o movimento que também a psicanálise contemporânea faz, mesmo que não seja em termos kleinianos.

Saliente-se ainda que ao intuir a possibilidade da técnica do brincar, Klein foi a primeira a pôr em prática a ideia da capacidade diurna de sonhar.

\section{Winnicott - o jogo da ilusão e desilusão na experiência de regressão à dependência}

Winnicott interessou-se pelo desenvolvimento emocional primitivo na perspetiva da total dependência do bebé em relação ao ambiente ou à atitude emocional da mãe, acrescentando tal como Bion e Green a defesa da importância da mãe real. Através do conceito de transicionalidade, que surgiu em 1951 na sua comunicação «Objetos transicionais e fenómenos transicionais» (Abram, 2007; Winnicott, 1975), introduziu outra revolução na psicanálise pela ligação com o domínio da ilusão e do jogo. Para ele, a ilusão e a desilusão são a base do jogo na relação com a mãe, a base também do que se entende por análise, chamando a atenção para a necessidade da vivência da regressão à dependência primordial no processo psicanalítico como condição para a emergência do verdadeiro self. A importância do indivíduo se poder experienciar a si próprio e comunicar é algo que passa a merecer um destaque com profundas raízes no desenvolvimento da mente primitiva, à semelhança do que irei mostrar com Bion.

Para Winnicott, é pela vivência das sucessivas adaptações da mãe ao seu bebé - a preocupação maternal primária, constituída pelo holding e o handling, que requerem não só o manuseamento físico, mas também a elaboração psíquica das experiências do bebé, demostrando capacidade de se identificar projetivamente com as necessidades deste - que vai ser possível a constituição no bebé do seu próprio sentimento de ser (going on being). A consolidação do status de unidade no qual a criança imagina que criou o objeto e que o objeto é parte de si, mesmo para lá do estado de necessidade, dará lugar ao estádio do concern (Caldwell \& Joyce, 2011), como transição para a imprescindível capacidade realista de relacionamento interpessoal.

Esta relação suficientemente boa com a mãe produz ainda o objeto transicional como uma fase ou estádio transicional no processo de simbolização, marcador do começo da perceção do self e do outro, num movimento do subjetivo para o objetivo. Separa o eu do não-eu, criando um espaço transicional entre ambos, condição para a vida criativa e saudável: da absoluta dependência para um estádio de uma dependência relativa, onde o bebé, ao perceber que a mãe não é ele mesmo, ganha a capacidade para criar o que precisa a partir daquilo que o ambiente lhe fornece.

O que não pode ser representado pela capacidade do par mãe-criança fica fora do conhecimento e é parte da realidade existencial que não é conhecida, podendo estabelecer-se uma equivalência à realidade $O$, incognoscível, que Bion preconizará.

A falha do ambiente neste estádio precoce traz como consequência o colapso ou breakdown que marca o trauma original, ou agonia primitiva, caracterizada por uma disrupção da unidade 
do self, frágil ainda para fazer frente a estas falhas (Abram, 2007). Esta agonia disruptiva, não mentalizável e além dos limites do representável, tal como Winnicott a concebe, pode considerar-se como uma deriva da ideia de Ferenczi de que «a mãe e o trauma são tecidos juntos» (apud Caldwell \& Joyce, 2011).

De acordo com Winnicott, o bebé lida com esta disrupção através da criação de uma invulnerabilidade, que acontece tanto no autismo como na esquizofrenia, onde um desligamento defensivo permite pôr o sofrimento à distância. Tal invulnerabilidade liga-se também ao alargamento do conceito freudiano de decatexia, que diz respeito, na descrição de Winnicott (1971), à transformação que a mãe suficientemente boa sofre devido a uma suficientemente longa ausência, trazendo também falhas de simbolização na esfera transicional. Como veremos adiante, esta ideia foi repegada por Green nos seus conceitos de mãe morta e função desobjetalizante. A decatexia pode ser vista ainda como um mecanismo de defesa que poderá aparecer no processo analítico no sentido de impedir o contacto com o trauma originário.

Sublinhamos que com Winnicott se inaugura, em linha de continuidade com Bion, a ideia de que não se trata unicamente de o analista e o paciente viverem juntos uma experiência, mas viverem juntos uma experiência não experienciada até ali, que pode mesmo ser o sentimento de existir.

\section{A «catastrófica mudança» na psicanálise com Bion}

O grande contributo de Bion para a metapsicologia dos estados primitivos da mente está patente em toda a sua obra, em dois planos. Inicialmente, pelo seu interesse acerca do modo como algo passa a ser representado, baseando-se nos seus trabalhos com grupos e na análise de pacientes psicóticos. Desenvolve uma teoria do pensar (1962), alarga o conceito kleiniano de identificação projetiva (1959) como o primeiro modo de intercomunicação entre a mãe e o bebé, e cria o modelo continente-conteúdo (1962), introduz- indo a função alfa da mente, aquela que transforma o que não é psíquico - beta - em elemento psíquico - alfa. Na chamada fase tardia, a partir da sua Teoria das Transformações (1965) e de Atenção e Interpretação (1970), volta-se para as transformações do não representado, dentro da zona indiferenciada $\mathrm{O}$, localizando aí as verdadeiras transformações em psicanálise $\mathrm{T}(\mathrm{O})$ - aquelas que não podem ser conhecidas, mas, sim, vivenciadas, o que significa vivenciar o que está para lá da representação (Vermote, 2013). Em termos clínicos, traduziremos pela possibilidade de o paciente «ser aquilo que realmente é», em continuidade com a experiência do verdadeiro self defendida por Winnicott, diferente e complementar ao conhecer.

Incorporando a importante dupla - Freud e Klein -, Bion expande assim a psicanálise pela formulação do sistema protomental, pela focagem na representação-coisa (Farate, 2018; Sandler, 2005), mas também pelo interesse nas transformações em $O$, num vetor infinito-finito, para lá do inconsciente-consciente (Vermote, 2013).

A ideia do protomental, que se pode enraizar no conceito de Id, surge da experiência de Bion (1961) com pequenos grupos, na sua fase dos grupos. Fonte de todas as emoções pré-verbais, é concebida como uma matriz onde o físico e o mental são indiferenciados, mas que integra a dinâmica inconsciente do próprio grupo em que o indivíduo se insere.

É um conceito que alarga a vida mental primitiva para a continuidade dinâmica entre vida pré-natal e pós-natal e para o domínio do gregário, numa visão não dualista do problema corpo-mente, indo assim além do interacionismo proposto por Freud no conceito de ego-corpóreo (Torres \& Hinshelwood, 2013; Farate, 2018).

E é nesta matriz biopsicossocial que Bion (1994) coloca as origens do pensar. As preconceções enquanto disposições inatas, constituintes do protomental e equivalentes aos noumena de Kant, organizam a vida porque correspondem a expectativas. A expectativa de um seio, em relação à qual, se houver uma realização positiva, constitui uma experiência emocional satisfatória pelo encontro com um pensador, dando origem a uma 
conceção. Na sua Teoria do Pensar (1962), Bion diz-nos que o primeiro pensamento é, no entanto, o seio ausente produzido pela capacidade do bebé para tolerar a frustração de uma realização negativa. Diferente do não-seio, onde não há esta capacidade e se gera, pelo contrário, um objeto mau, indistinguível de uma coisa-em-si, que se presta apenas à evacuação, vista como tentativa de obter alimento de um seio bom.

A representação-coisa será o melhor dos caminhos que as impressões inscritas na vida protomental podem seguir. Derivada dos traços mnésicos, consiste assim numa tradução em imagens mnésicas diretas da coisa, aquém ainda das possibilidades de expressão verbal e equivalentes à ideia de memória-ecrã de Freud. E é através do modelo desintoxicante continente-conteúdo derivado da identificação projetiva -, da rêverie e da função alfa, como mais adiante mostraremos, que estas primitivas inscrições se poderão transformar em elementos que constituem a linguagem pré-léxica, os ideogramas, ou, pelo contrário, poderão falhar e tornar-se objetos excretáveis que irão constituir a parte psicótica da personalidade, de acordo com Meltzer (2008, 1992) num nível de erotismo anal, podendo criar «vida num claustrum» (Sousa Lima, 2017).

Depois de 1961, Bion deixa de falar de sistema protomental para passar a utilizar o conceito equivalente de elementos beta, acrescentando também, de modo similar a Freud quando falava da pulsão, a ideia de uma demanda de trabalho sobre a psique - a função alfa ou a betalfabetização, dando origem aos elementos alfa. O mesmo será dizer conteúdos que invadem o feto ou o bebé, e que através da identificação projetiva comunicam a procura de alojamento em algum lugar - um continente -, ele próprio aberto a novos conteúdos vindos desse desconhecido; ou que invadem o adulto que tenta conter, em forma de palavras, essa experiência «inimiga».

Estas elementares partículas alfa são comparadas a blocos de lego, fornecendo à psique material para pensamentos oníricos. Armazenados e transformados, constituem a protetora barreira de contacto, possibilitando a melhor interação entre o consciente e o inconsciente.
Nos seus últimos contributos, de acordo com Vermote (2013), Bion volta-se para o que acontece no plano indiferenciado, interessando-se pelo modo como essas mudanças se podem iniciar ou pelo menos como podem não ser inibidas pelo analista, considerando que estão aqui as verdadeiras transformações em psicanálise $\mathrm{T}(\mathrm{O})$, o que ressignifica e redimensiona os conceitos anteriores. O sonho assume aqui um papel central enquanto reflexo destas mudanças.

\section{André Green e a função estruturante do trabalho negativo}

O contributo de André Green, que abordaremos através da breve referência a dois dos seus trabalhos - o trabalho do negativo e a mãe morta -, interessa-nos para a compreensão do vazio, responsável por dificuldades que certos pacientes enfrentam para fazer uso do setting analítico e da vida.

Interrogações acerca dos chamados estados-limites levaram ao esboço em 1974 da noção de trabalho do negativo, apenas proposto enquanto conceito em 1993, com vários sentidos: um estado de ausência, onde algo continua a existir; um limite e uma diferenciação, um Não, que inaugura de forma simbólica a constituição do psiquismo; um nada ou vazio, onde algo escasso existiu, ou chegou mesmo a não ter existência.

Os dois primeiros organizam-se através da função objetalizante, numa vertente estruturante que nos acrescenta a ideia da função crucial da alucinação negativa da representação do objeto primário, onde deverá acontecer um apagamento do objeto absolutamente necessário, condição imprescindível para que se crie um espaço interno ou continente psíquico - a estrutura enquadrante, uma estrutura psíquica na qual as representações possam ter origem e dar também nascimento a objetos substitutos (Green, 1998). O objeto tem de saber ocupar um lugar paradoxal de compromisso entre continuar a estimular e conter a pulsão nas suas desmesuras, mas ser capaz da função de falhar, distanciando-se. Só assim poderá ser produzida a inscrição da sua ausência como 
presença potencial, dando lugar aos fenómenos psíquicos, à espera inerente ao desejo e à possibilidade de retirar prazer dessa espera, no plano do sonho. De resto, em grande sintonia com os trabalhos de Winnicott acerca da preocupação maternal primária e de Bion sobre a origem do pensar, com quem Green mantinha amizade e ligação intelectual.

Nas situações de vazio, o trabalho do negativo falhou, predominando a desobjetalização e o desligamento que se organizam através dos mecanismos de defesa primitivos, como a forclusão, a negação e a clivagem. Falha a realização da perda e a possibilidade de reencontro, o que se traduz clinicamente numa excessiva dependência ou rejeição do objeto, neste último caso muitas vezes mascarada de autossuficiência. Instala-se uma oscilação paradoxal entre a angústia de separação e a angústia de intrusão, que evidencia uma fragilidade na constituição dos limites psíquicos e afeta a formação do pensamento e do desejo.

Por outro lado, queixas de insucesso, com atividade frenética, em muitos pacientes podem mascarar transferências de um luto branco, explicado por Green através do complexo da mãe morta, que clinicamente não se revelam logo no início do processo analítico. Este conceito deriva da sua noção de trabalho do negativo, como consequência da sua falha, e da sua teoria da representação. Explica-nos Green (1998) que não se trata das consequências psíquicas da morte real da mãe, mas, sim, de um imago que se constitui na psique da criança, em figura distante, átona, quase inanimada, morta psiquicamente aos seus olhos e de quem ela cuida, carregando assim a sombra do objeto.

\section{O CONCEITO DE TRABALHO ONÍRICO}

\section{Alargamento do conceito de sonhar-função alfa, rêverie, intuição e interpretação}

O sonho é para Bion o reflexo das transformações ou mudanças psíquicas que acontecem no nível mais indiferenciado da mente, o infinito sem forma, e Grotstein (2007) considerou-o como o representante «terrestre» da Verdade Última, distinguindo-se conceptualmente da ideia de trabalho onírico de Freud apenas enquanto salvaguarda do sono, protegendo a mente do retorno do reprimido, associado a desejos infantis.

Nesta perspetiva, é através dele que podemos ter acesso às mais profundas e verdadeiras mudanças psíquicas, e assim o abordaremos, enquanto transformação em $\mathrm{O}, \mathrm{T}(\mathrm{O})$, incluindo os últimos contributos de Bion.

Para Dana Birksted-Breen (2016), o trabalho onírico é o fomentador do pensamento regressivo e um exemplo particular de trabalho analítico, onde uma situação emocional premente é colocada numa representação gráfica, usando para isso episódios e imagens recentes disponíveis, que são resíduos do dia. Por si só traz mudanças mentais no paciente, porque algo foi psiquicamente trabalhado e transformado em representação de sonhos. Nesse sentido, não é apenas o processo de transformação em representação gráfica, mas também um processo de trabalho através do qual o sofrimento psíquico se torna elaborável, concretamente pelo uso do espaço do sonho como um recipiente.

Criada por Bion em 1960, enquanto formulação, a função alfa da mente é a grande «agência produtora» de sonhos, composta pela rêverie, intuição e a dream work. De acordo com Meltzer (2008), um aparelho que desempenha a função de processar experiências emocionais e impressões sensoriais, ocorridas tanto no estado de vigília quanto no de sono, de forma que se gerem pensamentos oníricos.

A rêverie, da qual Bion fala pela primeira vez em 1959 e desenvolve em 1961, ligada à sua Teoria do Pensar, é um estado onírico, aberto à receção de qualquer objeto, sentido como bom ou mau, proveniente das identificações projetivas do bebé ou do analisando e que requer capacidade de tolerar frustração, capacidade negativa e ausência de resposta imediata ou acting. Dito de outra forma, um continente com suspensão da consciência, temporariamente liberto do concreto, factual, do realismo, com foco no interior, que nos leva de $\mathrm{O}$ em direção a $K$ para que $\mathrm{K}$ transforme $O$. Equivalente também ao trabalho de figurabilidade defen- 
dido por Botella \& Botella (2007), que acentua a importância da capacidade de tolerar regressão no pensamento, podendo igualmente situar-se no espaço transicional de Winnicott.

Enquanto estado adormecido da mente, ao serviço de Eros, que se assemelha ao estado materno do cuidar amoroso, possui um radar que é a intuição. Carla Cruz (2018) diz que é «através dela que o analista capta aquilo que está para além do discurso, isto é, para além do símbolo» (p. 53). Coloca-a no centro da vivência analítica, considerando que o «conceito de identificação projetiva permitiu conhecer como os objetos internos são projetados para "dentro" da pessoa do analista e é neste jogo intersubjetivo que os silêncios, o tom de voz, os ruídos, os gestos, os odores, etc. definem a qualidade da presença» (p. 31). Ainda de acordo com a autora, a intuição permite gerar novos elementos no psiquismo do analista: sensações, ideias e interpretações.

O uso criativo da rêverie com a suspensão da memória e desejo será da responsabilidade do a dream work (Bion,1961,1992/1959; Dias, 1998), a atividade da mente humana, responsável pela produção de representações visuais de forma contínua - os pictogramas - tanto de noite como de dia. São imagens que vêm a gerar metáforas verbalmente simbólicas, com diminuição da rejeição do pensamento assimétrico do analista e transformação da massividade das projeções do paciente, operando como um terceiro elemento, promotor de um maior espaço psíquico e da necessária triangulação. Criam também as condições ótimas para a simbolização, preservando estas personalidades de um excesso insuportável de estímulos dolorosos, que não conseguiriam metabolizar.

Nesta linha de pensamento, a dupla transferência-contratransferência é vista à luz do modelo continente-conteúdo e todo o material de uma sessão pode ser analisado «sonhando a sessão» (Freud,1911; Alexandre, 2014), onde o analista na posição de «trabalhador criativo» (Bion, 1992/1959) simula o estado emocional do analisando de modo sensível e íntimo, «tornando-se o analisando» (apud Groststein, 2017). Incluímos aqui o sonho noturno trazido pelo paciente para continuar a ser sonhado no par analítico, com os pesadelos como exemplos extremos de situações em que a capacidade de gerar pensamento onírico é interrompida, originando um estado de temor que requer a mente de outra pessoa.

Isto acontece esquecendo as sessões anteriores, as teorias, o desejo de curar, os dados da realidade externa, pelo despojamento e recetividade na rêverie, que é o estado de sem memória e sem desejo. Ele dará origem à produção de imagens metafóricas a partir das quais emergirá $o$ facto selecionado, uma chave associativa que confere significado às associações posteriores e às seguintes, permitindo novas ligações necessárias à construção da interpretação. Por sua vez, este fará surgir, no paciente, o que Pichon Riviére chama de «ponto de urgência» (Baranger, 1993), um momento assimétrico de mutação, no sentido de Matte Blanco (1975), onde uma transformação em $\mathrm{T}(\mathrm{O})$ progride para $\mathrm{T}(\mathrm{K})$ e altera $\mathrm{T}(\mathrm{O})$, transformando assim uma ansiedade primitiva.

É importante que o facto selecionado não se confunda com ideia sobrevalorizada, um fenómeno defensivo que pode ser usado pelo analista pelo desejo de integrar experiências díspares e confusas. De acordo com Britton e Steiner, «no caso de uma ideia sobrevalorizada, a integração é espúria e resulta dos factos serem forçados a ajustarem-se a uma hipótese ou teoria que o analista precisa para propósitos defensivos» (1994, p. 1070). Daí que toda a intervenção ou interpretação deverá ser colocada ao paciente como uma hipótese e avaliada de acordo com a expansão mental impossível de acontecer quando se geram enunciados falsos promotores de um falso self no paciente, e nós cegos no analista.

De acordo com Aragão (2019), a interpretação parece assim estar para lá da capacidade consciente do analista. O autor diz-nos que «o foco não é mais no pensamento ou na transformação em conhecimento $\mathrm{T}(\mathrm{K})$ que tem lugar no plano das representações, mas nas mudanças psíquicas no plano experimental/vivencial, ao nível da não representação». E acrescenta ainda que «para ocorrer interpretação psicanalítica ambos os processos $\mathrm{T}(\mathrm{K})$ e $\mathrm{T}(\mathrm{O})$ devem estar presentes no mundo mental do analista num processo 
de interação dinâmica». Perspetiva que se pode ligar à ideia de que a interpretação pode levar à construção com o mesmo valor de recaptura de memória, tal como Freud se veio a aperceber em Construções em Análise (1937).

\section{À PROCURA DA EXPERIÊNCIA ONÍRICA: ILUSTRAÇÃO CLÍNICA}

\section{O dinossauro e a lâmpada mágica. Um exemplo de criação do brincar e de construção do significado}

António tem três anos quando nos chega, com diagnóstico de autismo. É o mais velho de dois filhos. A mãe diz que «foi desejado, um bebé muito sossegado e dorminhoco, agora desembaraçado e autossuficiente», para ela boas qualidades. $\mathrm{O}$ atraso na fala é o problema que a levou a pedir ajuda, com o pai. Acrescenta que «por frustrações laborais que já se vinham acumulando, foi-se abaixo, depois de voltar ao trabalho, quando António tinha quatro meses e durante o seu primeiro ano de vida». Do seu passado, diz-nos não ter conhecido o seu pai porque morreu de acidente durante a sua própria gravidez, afirmando que para si é algo já ultrapassado. A preocupação do pai de António é, «para além do atraso na fala, o filho não brincar, bater com a cabeça e bater-se a si próprio quando contrariado», o que o deixa com um sentimento de impotência, sem saber como resolver.

Em ambos, pai e mãe, se destaca um funcionamento racional e intelectualizado com uma partilha entre eles preponderantemente no plano ideológico.

A meio do processo analítico, António passou a vir às sessões acompanhado pelo pai, percebendo-se mais proximidade entre ambos; e depois, já perto do fim, era trazido alternadamente por pai ou mãe, o que coincidia com algumas melhorias na organização familiar.

\section{No começo, foi a musicalidade}

No início, a falha no plano da simbolização era evidente em António. Não falava, emitia ape- nas sons e guinchos. Aparentemente, ignorava a minha presença, interagindo de forma mecanizada sem olhar nos olhos. À entrada, perante o convite para brincar, agarrava-se às pernas da mãe como se fossem um só, mas ao mesmo tempo estendia a mão para que eu o conduzisse à sala, sem me olhar. Pouco ligava aos brinquedos; se os agarrava, abandonava de seguida, com indiferença.

Nos primeiros dois meses, recusava separar-se da mãe. Agarrava-se chorando de forma violenta e era a analista que confortava com as palavras. A mãe permanecia na sala, absorta e desligada perante a dor da separação, e aqui António ignorava-a.

Desta forma, e desde os primeiros momentos, delineou a intensidade da sua dor, oscilando entre a introjeção da minha presença e a resposta autossuficiente como refúgio psíquico. Nesta oscilação, foi-se interessando, por curtos momentos, pelos brinquedos, pelos objetos fofos, pela minha ajuda, pelo meu interior. Ousou espreitar para dentro das orelhas, para dentro da boca, alternando com um deambular perdido e desligado pela sala. Em rêverie, fui sempre «musicando» com a melhor história possível - a do menino perdido e muito assustado - , de forma que esta narrativa pudesse funcionar como um continente sonoro, produzindo um envelope sonoro, delimitador do caos. Em alternativa a uma hipotética barreira autista? Ou forclusão? Como saber nesta altura? Seria preciso tempo.

Nesta fase inicial do encontro analítico, era a melodia que tinha o poder de desencadear a transformação, através das sensações auditivas e visuais. Depois, estas, associadas à palavra, permitiram ir construindo fragmentos narrativos integrados numa cadeia de significados, conectadas com afetos, ou seja, representações que viriam a contribuir para a estruturação da linguagem verbal. E deste modo, foi-se gradualmente constituindo a ponte para o restabelecimento da relação com o objeto, que teria sofrido disrupção precoce.

António ligou-se a uma bola fofa e com ela jogou à ausência-presença. Atirava para longe, ia buscar e abraçava, e eu ia narrando musicalmente, até que, numa das vezes, ao abraçar, disse 
«bô!» (bola). Noutra sessão de grande impacto, interrompeu este jogo, deambulou pela sala, agarrou numas tiras de papel de cenário, saiu da sala, foi ter com a mãe à sala de espera e começou a envolvê-la com elas, provocando-me a imagem de uma mãe moribunda envolvida em ligaduras. Apontou-lhe para os olhos e senti neles uma profunda tristeza. Disse: «O António quer dizer à Conceição que a mãe está triste? Quer que a Conceição trate o dói-dói triste da mamã?» A mãe, enterrada e encolhida no sofá, sorriu com expressão melancólica.

Foi surpreendente a qualidade das suas associações livres e esta espécie de lucidez, talvez o saudável juiz silencioso de que nos fala Grotstein. António estaria a mostrar o objeto interno, desvitalizado, que carregava.

Pelo terceiro ano de análise, articulava, fluente e expressivamente, sons no dialeto enfático, dando sinais de ir introjetando a musicalidade da analista. Também utilizava bastante as tintas. Carrinhos e bonecos eram pintados de preto, sessões após sessões, inclusive uma Barbie grávida, sem o bebé lá dentro e sem o interior pintado. Um buraco branco num corpo negro, que deixaria o negativo na mente da analista - um buraco negro num corpo branco. Sem dúvida outra imagem muito forte. A sua mãe estaria grávida? António tentaria representar o seu vazio dentro do vazio materno? Passado pouco tempo, confirmou-se que iria ter um irmão.

Seguiu-se outro conjunto de sessões, que alternavam a pintura de carros e boneca com a lavagem destes em água tépida. Depois de os lavar, mergulhava-os, e assim permanecia, a sentir o conforto da água nas suas mãos. Conto a história dos carrinhos tristes, da mamã triste que não sabe do bebé e do bebé que não sabe da mamã, e o carrinho também não sabe do bebé. Aproveito este momento de conforto da água nas suas mãos para mais uma vez ligar a sensação à palavra. Digo que a água quentinha/Conceição faz bem ao dói-dói triste. Coloco lá também o bebé para dizer que na água quentinha/Conceição podem ficar tristes e depois não ficar. Ouve atento e sorri. No final, os objetos são envoltos numa toalha, tal como as suas mãos, «onde ficam sossegadinhos», como marca da presença da função alfa na dor da perda e do vazio. Pede com a ajuda de gestos a repetição deste jogo.

Mas a insegurança da perceção de outros bebés/pacientes que iam ali, tal como o que iria acontecer com a sua mãe, levaram a uma regressão. Rejeitou a minha presença, ameaçadora da fusão com a a mãe. Fez de novo birras intensas, a sala ficava num caos, com peças de lego espalhadas pela sua fúria, e eu interpretava a sua zanga e o seu medo. Juntei as peças e fiz uma casinha/ Conceição onde todos os meninos têm lugar para brincar, dizendo que «o António queria a Conceição só para ele, a mamã só para ele». E ele participou no jogo/interpretação. Colocava os bonecos fora da casinha de legos, à porta, e fazia-os entrar, até que decidiu mesmo ampliar o espaço para caberem todos.

\section{Entre o desespero e a esperança. No infinito sem forma}

Numa outra fase mais avançada da sua análise, brinca à «pizaria louca» - «a atração pelo terror» - uma reprodução de algo que joga on-line, a representação possível para o seu caos, num mundo à parte.

Duas crianças vão lá comer pizas. Aparece o Megatronic a fazer animação, atrai-as para um quarto e mata-as. Reveste este boneco a plasticina fazendo-lhe um fato de monstro. Não podia fazer movimentos, nem rir, porque este fato lá dentro tinha molas com facas e matava. Digo-lhe que deve ser horrível viver dentro desse fato, da cor do cocó, sem se poder mexer, só para atrair as crianças e matar. Recusa a minha proposta de os pais as acompanharem, pois explica que é para fazermos como se eles não estivessem dando conta tanto da sua solidão como da proporcional omnipotência. Nenhuma intervenção minha é permitida.

No final, anuncia que na sessão seguinte será a vingança das almas das criancinhas. Uma vingança sangrenta. Megatronic fica coberto de plasticina vermelha, inundado de sangue. E ele pergunta se acho justa a vingança das crianças. Digo que consigo compreender a fúria das crianças, porque o 
mundo lhes fez mal, mas parece que elas só se podem zangar quando estão mortas, pois vivas é mais difícil; que precisamos de tomar conta delas e também do Megatronic. Desta vez, foi aceite a proposta de os levar ao hospital de ambulância.

Ambulâncias, polícia, pais e hospital vão sendo uma diferença delimitadora deste caos, acolhida por ele. Naquele hospital, os meninos falam da sua zanga e podem ficar tristes. Os pais estão lá também. E ele ouve atento a história daquele hospital. Sai pensativo a olhar para o chão. É de notar também que o fato de plasticina foi desmantelado: o homem saiu de lá de dentro e António explica que o fato fica vazio.

$\mathrm{Na}$ minha rêverie, o fato desativado emerge como uma boa imagem representativa do preço a pagar quando se passa da posição esquizoparanóide para a posição depressiva —o vazio.

\section{A disrupção do sentimento de ser}

Apresentarei agora excertos que emergiram em ambiente calmo e caloroso, muito representativos da disrupção da vida de António. O jogo que vinha sendo jogado é abruptamente interrompido pela dor do vazio, anteriormente preenchido por facas mortíferas. Arrisco esta interpretação do fato que fica vazio e ele passa a poder brincar à interrupção.

Propõe o jogo das escondidas, mas quem aparece é o seu clone, devolvendo-lhe que «o clone vem no seu lugar porque ele tem um segredo e ainda não tem palavras para o contar». Retoma o jogo com bonecos onde há uma mãe muito bonita, mas muito pobre, que não consegue proteger os seus dois filhos, mortos pelo «homem normal» que saiu de dentro do Megatronic. Explica que as duas crianças estavam sentadas na beira da autoestrada e ninguém as via, por isso, foram atropeladas por ele. Interrompe o jogo, deita-se no chão, de barriga para cima e braços abertos, numa forte expressão $\mathrm{O}$ - em abertura e entrega. Pergunta-me o que fazia se encontrasse um assassino, se o salvava. Respondo que sim, e ele continua indagando o que fazia se existissem no mundo só eu e alguém que me quer matar, se o salvaria. Devolvo o quão difícil e duro isso deveria ser. Se matasse, ficaria sozinha no mundo - mas até parece sentir que ou mata ou então é morto. Ergue-se e fica sentado no chão à minha frente, com lágrimas nos olhos.

A chorar, questiona de novo: «Que fazias se alguém te dissesse que se suicidar é o melhor sonho da sua vida? Salvavas? É um direito que ela tem, querer morrer. Porque a sua vida é uma merda.» Comento: «Não gostas de ti.» Deita-se e senta-se de novo. «Não, não gosto. E o meu melhor sonho desde pequenino é suicidar-me. Quero estar no céu em paz. Estou farto de viver neste corpo» Acolho, afirmando que deve ser terrível sentir-se assim no seu corpo e que agora percebemos melhor o Megatronic, com aquele fato feito de sentimentos maus dentro dele como facas, mas que estamos aqui para que possa construir outro sonho muito melhor do que se matar. As lágrimas caíram, em silêncio.

Num retorno de férias de verão, António trazia na mão um dinossauro e uma minúscula lâmpada mágica para brincarmos. A analista seria a lâmpada mágica, como se sempre soubesse o quanto esta precisa dela para manter viva a ilusão, revitalizando partes da sua mente que correm o risco de ser engolidas pelo vazio do objeto interno. E que é a lâmpada mágica senão a rêverie transformadora de um infinito sem forma em conteúdos inconscientes pensáveis, que agora pode representar pela palavra dinossauro?

\section{Comentário à ilustração clínica}

A turbulência emocional dos primeiros contactos com o nosso paciente, de forte impacto na minha mente, coloca-me perante complexas manifestações de estados muito primitivos da mente, levando a várias interrogações: António, que começa por ignorar a minha presença e depois também a da mãe, tem a perceção do objeto? Estaremos ou não perante níveis anteriores à posição esquizoparanóide, onde uma parte da sua mente não pôde nascer? Quão precoce foi a disrupção materna? Qual o lugar do pai/terceiro no filho e na mãe? 
As suas reações violentas à separação e à vivência do buraco no corpo da mãe como um buraco e um vazio dentro de si mesmo fazem pensar em sentimentos de aniquilamento, que apontam para estados de não perceção do objeto, contra os quais desenvolveu uma concha protetora onde se refugia da dor e dentro da qual fica absorvido em atividade autossensorial e em autossuficiência.

Por outro lado, a musicalidade que produziu transformações, desde o início, promovendo a procura fora da concha - o interesse pelos brinquedos, pelos objetos fofos, pelo interior da analista - , coloca-nos perante o fenómeno da identificação projetiva a um nível mais organizado do que a equação adesiva. A bola fofa, designada por «bô», anuncia os primórdios de um objeto com significado simbólico - um pré-objeto transicional, como primeira pedra para a ponte entre self e objeto. De igual modo, a aceitação da construção de uma casinha para elementos beta expelidos perante o terror sem nome demonstra um movimento para estados em PD mais integrados, quando a função alfa está presente. No extraordinário diálogo existencialista com a analista, depois de interromper o brincar e de em seguida poder representar essa interrupção, usa a finitude da palavra para exprimir a sua profunda infelicidade do desencontro com o objeto que durante estes anos permaneceu no corpo, sob a forma de ecrã beta - as facas do Megatronic, tornando-o na vítima e no assassino ao mesmo tempo, no assassino que recusámos matar, dizendo-lhe que merecia viver, experienciando com a analista algo que não havia experienciado ainda. Pela função alfa, estes elementos não integrados foram-se transformando em formas mais finitas, pensáveis e organizadoras do caos: a infelicidade, o suicídio, viver no céu em paz.

Sintonizamos com Durban (2019) quando fala de autismo de espectro psicótico, considerando-o diferente do puro autismo, dada esta espécie de «comorbilidade» com a psicose. $\mathrm{Na}$ classificação da psicanálise francesa, é também designado por estruturas pré-psicóticas. A estrutura psicótica aparece misturada com defesas autistas, parecendo que as últimas podem servir como um refúgio para as primeiras.
Sintonizamos também com Sousa Lima (2017), quando ao evocar Klein diz que o medo de aniquilamento por forças destrutivas internas, ou o terror sem nome para Bion, é o maior dos medos, enquanto Tustin (1990) fala mesmo da ameaça de perder a noção da existência. E assim, só uma combinação autístico-psicótica, onde o paciente tem de recorrer, tanto à concha autista como à identificação projetiva massiva e à omnipotência/forclusão, parece protegê-lo do caos e da desintegração.

Exemplificando o que De Masi defende, esta dinâmica ilustra os estados primitivos malformados desde a origem pela falência do objeto, voltado para dentro da sua depressão, na perspetiva de Green, e que o filho carrega dentro de si numa zona indiferenciada que não tinha encontrado ainda pensamento.

\section{CONSIDERAÇÕES FINAIS}

O conceito de estados primitivos da mente expande a dimensão do infantil para níveis de organização e inscrição de fenómenos que não podem ser considerados psíquicos ainda, mas, sim, protopsíquicos, integrando também em si a ideia das transformações que aqui podem ocorrer como as mais profundas transformações em psicanálise. Em termos teórico-clínicos, este conceito implica uma ceasura entre o conhecimento e a vivência da experiência, passando esta última a ter um lugar muito importante no processo psicanalítico, visto como um campo psíquico. $\mathrm{O}$ sonho constitui-se como reflexo destas transformações protopsíquicas e é assim o melhor dos instrumentos para o contacto com elas e para as promover, de modo que se gere pensamento e nascimento psíquico a cada momento.

Finalmente, este artigo empreende uma reflexão compreensiva acerca da complexidade desta realidade psíquica, em relação à qual deverá ser sempre valorizada a interligação dos aspetos constitucionais e ambientais, mostrando a necessidade de integrar teorias, sob a égide da experiência clínica. 


\section{BIBLIOGRAFIA}

Abram, J. (2007). The Language of Winnicott: A Dictionary of Winnicott's Use of Words. Karnac Books.

Alexandre, M. F. (2014). A experiência psíquica. Ensaios sobre a construção do processo psicanalítico. Fenda.

Aragão, R. (2019). Da interpretação: lugar e oportunidade para o objecto psicanalítico. Revista Portuguesa de Psicanálise, 39 (1), 7-9.

Baranger, M. (1993). The Mind of the Analyst: From Listening to Interpretation. The International Journal of Psychoanalysis, 74, 15-24

Bion, W. R. (1961). Experiences in Groups and Other Papers. Routledge.

Bion, W. R. (1962). Learning from Experience. Heinemann/Basic Books.

Bion, W. R. (1963). Elements of Psychoanalysis. Karnac Books.

Bion, W. R. (1965). Transformations. Karnac Books.

Bion,W. R. (1970). Attention and Interpretation. Karnac Books.

Bion,W. R. (1992/1959). Cogitations. Karnac Books.

Bion, W. R. (1994). Estudos Psicanalíticos Revisitados (Second Thoughts). Imago.

Birksted-Breen, D. (2016). The Work of Psychoanalysis: Sexuality, Time and the Psychoanalytic Mind. Routledge.

Britton, R. \& Steiner, J. (1994). Interpretation: Selected Fact or Overvalued Idea? The International Journal of Psychoanalysis, 75, 10691078.

Botella, C. \& Botella, S. (2007). La Figurabilité Psychique. Editions in Press.

Bottela, C. \& Bottella, S. (2013). Psychic Figurability and Unrepresented States. In H. B. Levine, G. S. Reed \& S. Dominique (Eds.), Unrepresented States and the Construction of Meaning (pp. 95-121). Karnac Books.

Caldwell, L. \& Joyce, A. J. (2011). Reading Winnicott. Routledge.

Caper, R. (1998). Psychopathology and primitive mental states. The International Journal of Psychoanalysis, 79, 539-551.
Cruz, C. (2018). A intersubjectividade na díada: fonte de intuição do analista. Tese para Membro Titular (não publicada). Sociedade Portuguesa de Psicanálise.

De Masi, F. (2009). Vulnerability to Psychosis: A Psychoanalytic Study of Nature and Therapy of the Psychotic Sate. Karnac Books.

Dias, C. A. (1998). $\alpha$ Dream Work. In A. M. Rezende; C. A. Dias; D. E. Zimerman, Bion hoje (pp. 13-36). Fim de Século.

Durban, J. (2019). Making a Person. Comunicação Pessoal na Maratona de Lisboa.

Farate, C. \& Jorge, M. S. (2018). Bion e Lacan para além de Freud. Ideias, signos e «palavras cruzadas» para uma psicanálise em mudança. Almedina.

Favero, A. B. \& Rudge, A. M. (2009). Trauma e desmentido. Psychologica, 50, 169-180.

Freud, S. (1899). Screen memories. In The Standard Edition of the Complete Psychological Works of Sigmund Freud, 3 (pp. 311-322). The Hogarth Press.

Freud, S. (1905). Três ensaios sobre a teoria da sexualidade. In Edição Standard Brasileira das Obras Psicológicas Completas de Sigmund Freud, vol. VII. Imago.

Freud, S. (1911). Formulações sobre os dois princípios do funcionamento mental. In Edição Standard Brasileira das Obras Psicológicas Completas de Sigmund Freud, vol. XII. Imago.

Freud, S. (1914). História do movimento psicanalítico. In Edição Standard Brasileira das Obras Psicológicas Completas de Sigmund Freud, vol. XIV. Imago.

Freud, S. (1920). Além do princípio de prazer. In Edição Standard Brasileira das Obras Psicológicas Completas de Sigmund Freud, vol. XVIII. Imago.

Freud, S. (1923). O Ego e o Id. In Edição Standard Brasileira das Obras Psicológicas Completas de Sigmund Freud, vol. XIX. Imago.

Freud, S. (1932). Novas Conferencias Introdutórias de Psicanálise. In Edição Standard Brasileira das Obras Psicológicas Completas de Sigmund Freud, vol. XXII. Imago.

Freud, S. (1937). Construções em análise. In Edição Standard Brasileira das Obras Psicológicas Com- 
pletas de Sigmund Freud, vol. XXIII. Imago.

Freud, S. (1915). Os instintos e suas vicissitudes.

In Edição Standard Brasileira das Obras Psico-

lógicas Completas de Sigmund Freud, vol. XIV. Imago.

Freud, S. (1938). Moisés e o Monoteísmo. In Edição

Standard Brasileira das Obras Psicológicas Completas de Sigmund Freud, vol. XXIII. Imago.

Green, A. (1998). The Primordial mind and the

work of negative. The International Journal of Psychoanalysis,79, 649-665.

Grotstein, J. S. (2007). A beam of intense darkness.

Wilfred Bion's Legacy to Psychoanalysis. Karnac Books.

Grotstein, J. S. (2017). “... no entanto, ao mesmo tempo e em outro nível...”: Aplicações clínicas na linha kleiniana/bionian, vol 2. Blucher.

Levine, H. B, Reed, G. S. \& Scarfone, D. (2013).

Unrepresented States and the Construction of Meaning. Karnac Books.

Matte Blanco, I. (1975). The Unconscious as Infinite Sets. Karnac Books.

Meltzer, D. (1992). The Claustrum. An Investigation of Claustrophobic Phenomena. Perthshire-Scotland. Clunie Press.

Meltzer, D. (2008). The Kleinian Development. Karnac Books.

Roussillon, R. (2011). Primitive Agony and Symbol- ization. Karnac Books.

Roussillon, R. (2015). A função do objeto na ligação e desligamento das pulsões. Livro Anual de Psicanálise, XXIX, 95-113.

Sandler, P. C. (2005). The Language of Bion. A Dictionary of Concepts. Karnac Books.

Symington, J. \& Symington, N. (2014). O Pensamento Clínico de Wilfred Bion. Climepsi Editores.

Sousa, M. C. L. (2017). Em que sítio da minha cabeça levo a Maria do Carmo? Da génese e destino da identificação projetiva. Freud \& Companhia.

Torres, N. \& Hinshelwood, R. D. (2013). Bion's Sources. The saping of his paradigms. Routledge.

Tustin, F. (1981). Autistic States in Children. Routledge \& Kegan Paul.

Tustin, F. (1990). The Protective Shell in Children and Adults. Karnac Books.

Vermote, R. (2013). Sobre o Valor das Últimas Contribuições de Bion para a Teoria e Prática Analíticas. Livro Anual de Psicanálise, XXVII-1,37-46.

Vermote, R. (2019). Reading Bion. Routledge.

Winnicott, D. W. (1971). Da Pediatria à Psicanálise. Obras Escolhidas (pp. 218-232). Imago.

Winnicott, D. W. (1975). O brincar e a realidade. Imago.

\title{
Primitive states of mind: the dream work in the analytic encounter
}

\begin{abstract}
The author displays a theoretical-clinical reflection about the primitive states of the mind, by defining this concept in dialogue with other classic concepts in psychoanalysis. Following a conceptual line that goes from Freud to the contributions of Klein, Winnicott, Bion and Green, she seeks to demonstrate the presence of the primitive states of mind in the psychoanalytic process. The author also highlights the use of dreamwork as a tool that allows the access to, and the transformation of, unrepresented states of the mind, and further illustrates clinically her hypothesis through the presentation and discussion of psychic material issued from the analysis of a child.
\end{abstract}

Keywords

Primitive states of mind, Unconscious, Reverie, Psychic transformations. 